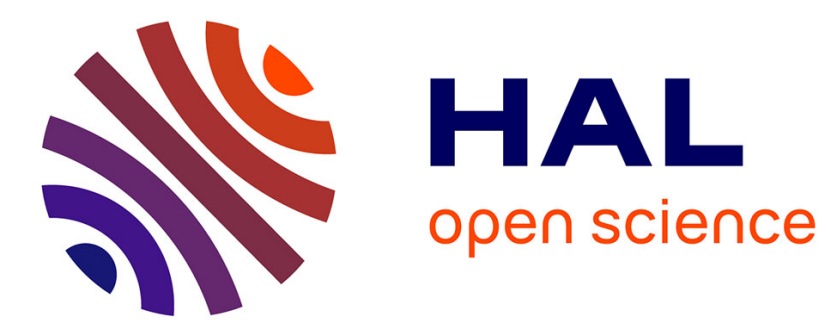

\title{
A new analysis of sound propagation near the critical point of xenon
}

\author{
B. Quentrec
}

\section{To cite this version:}

B. Quentrec. A new analysis of sound propagation near the critical point of xenon. Journal de Physique Lettres, 1979, 40 (13), pp.257-261. 10.1051/jphyslet:019790040013025700 . jpa-00231620

\section{HAL Id: jpa-00231620 https://hal.science/jpa-00231620}

Submitted on 1 Jan 1979

HAL is a multi-disciplinary open access archive for the deposit and dissemination of scientific research documents, whether they are published or not. The documents may come from teaching and research institutions in France or abroad, or from public or private research centers.
L'archive ouverte pluridisciplinaire HAL, est destinée au dépôt et à la diffusion de documents scientifiques de niveau recherche, publiés ou non, émanant des établissements d'enseignement et de recherche français ou étrangers, des laboratoires publics ou privés. 


\title{
LE JOURNAL DE PHYSIQUE-LETTRES
}

Classification

Physics Abstracts

$64.70-51.40$

\section{A new analysis of sound propagation near the critical point of xenon}

\section{B. Quentrec}

Laboratoire de Physique de la Matière Condensée (*), Université de Nice, Parc Valrose, 06034 Nice Cedex, France

(Reçu le 19 mars 1979, révisé le 9 mai 1979, accepté le 15 mai 1979)

\begin{abstract}
Résumé. - Nous donnons une nouvelle analyse des données expérimentales montrant que la dépendance en fréquence observée dans l'absorption et la dispersion du son près du point critique du xénon, n'est pas seulement due, comme on le croyait jusqu'à présent, aux modes couplés d'entropie, mais est due également aux inhomogénéités de densité. La théorie de l'ordre local qui rend compte de ces inhomogénéités donne une description correcte des données pour $T-T_{\mathrm{c}} \geqslant 1^{\circ} \mathrm{C}$. Nous trouvons, pour la viscosité de volume une loi de divergence en
\end{abstract}

$$
\left(T-T_{\mathrm{c}}\right)^{-1,92}
$$

en très bon accord avec les prédictions de Kawasaki.

\begin{abstract}
We give a new analysis of experimental data showing that the frequency dependence observed in the absorption and dispersion of sound near the critical point of xenon is not only due, as believed up to now, to the entropy mode coupling but is also due to the density inhomogeneities. The local order theory which takes into account these inhomogeneities gives an accurate description of the data for $T-T_{\mathrm{c}} \geqslant 1{ }^{\circ} \mathrm{C}$. We find for the bulk viscosity a divergence law of the form $\left(T-T_{\mathrm{c}}\right)^{-1.92}$, in very good agreement with Kawasaki's prediction.
\end{abstract}

The analysis of sound propagation near the critical point has already a long history. Using mode mode coupling theory, Kadanoff and Swift [1] were the first to predict the divergence of $\theta=\frac{1}{\rho_{\mathrm{c}}}\left(\eta_{\mathrm{B}}+\frac{4}{3} \eta_{\mathrm{S}}\right)$ where $\eta_{\mathrm{B}}, \eta_{\mathrm{S}}$, and $\rho_{\mathrm{c}}$ are respectively the bulk viscosity, the shear viscosity and the critical density. Some time later, Kawasaki [2] computed the frequency dependence of $\theta(\omega)$ and thus obtained the sound attenuation $\alpha(\omega)$ and the sound velocity $C(\omega)$. Eden, Garland and Thoen [3] compared these expressions with their experimental results and found a reasonably good agreement between theory and experiment. However, recently Sarid and Cannell [4] gave a new analysis of Mueller, Eden and Garland's [5] experimental data using recent values of the critical exponents and showed that there is an important discrepancy which can reach a factor of ten between Kawasaki's predictions and experiment. Kawasaki assumes that the only relevant variables of the problem are the entropy modes $S_{q}$, the transverse components of the velocity $V_{q}^{\mathrm{T}}$ and the mode mode coupling $S_{q-k} S_{k}$ and $S_{q-k} V_{k}^{\mathrm{T}}$. But the arguments for neglecting the density modes $\rho_{k}$, the longitudinal velocity modes $V_{q}^{\mathrm{L}}$ and their

(*) Laboratoire associé au C.N.R.S. nº 190. coupling are not very clear and a complete analysis should include all five usual hydrodynamic modes and their coupling. Unfortunately this is a very difficult task which, to our knowledge, has not been undertaken up to now. In a recent paper, Quentrec and Oppenheim [6] introduced a tensor $\overleftrightarrow{G}$ to take into account the density inhomogeneity of the fluid near the critical point. They showed that this tensor is a slow variable. Using Mori's projection operator technique and a semi phenomenological approach [7] they were able to obtain the equations of evolution for the five usual hydrodynamic variables plus the tensor $\overleftrightarrow{G}$. Thereafter we shall refer to this work as the local-order theory, and we shall use this theory to give a new analysis of the sound propagation data of reference [5].

The fundamental equations of reference [6] are :

$$
\begin{aligned}
\overleftrightarrow{\pi}_{\mathrm{s}} & =-2 \eta_{\mathrm{s}}(\nabla \mathrm{V})_{\mathrm{s}}-2 \alpha_{12} \dot{\vec{G}}_{\mathrm{s}} \\
\overleftrightarrow{a G}_{\mathrm{s}} & =-2 \alpha_{12}(\nabla \mathrm{V})_{\mathrm{s}}-2 \alpha_{22} \dot{\vec{G}}_{\mathrm{s}} \\
\pi_{\mathrm{t}} & =-3 \eta_{\mathrm{B}} \nabla \cdot \mathrm{V}-3 \varepsilon_{12} \dot{G}_{\mathrm{t}} \\
\mathrm{d} G_{\mathrm{t}} & =-3 \varepsilon_{12} \nabla \cdot \mathrm{V}-3 \varepsilon_{12} \dot{G}_{\mathrm{t}} \\
\mathbf{J} & =-\lambda \nabla T
\end{aligned}
$$


where $\pi_{\mathrm{t}}$ and $\pi_{\mathrm{s}}$ are respectively the trace and the traceless part of the viscous stress tensor, $\mathbf{J}$ the heat flux, $\lambda$ the thermal conductivity. The $\alpha_{i j}$ and $\varepsilon_{i j}$ are new transport coefficients.

The equations (1), (2), (3) and the usual conservation laws give a complete set of equations which can be easily solved.

The $\overleftrightarrow{G}$ tensor plays a role similar to the density mode mode coupling $\rho_{k-q} \rho_{q}$ since those two variables take into account the density inhomogeneity of the fluid and it is shown in reference [6] that in fact $\overleftrightarrow{G}$ is a special linear combination of $\rho_{\boldsymbol{k}-\boldsymbol{q}} \rho_{\boldsymbol{q}}$.

Nevertheless the equations (1), (2), (3), do not take into account $S_{q-k} S_{k}$ and $S_{q-k} V_{k}^{\mathrm{T}}$ and they must be considered as a complete set of equations after elimination of these last variables. As usual in such a case, the transport coefficients $\eta_{\mathrm{S}}, \eta_{\mathrm{B}}, \lambda$, and the $\alpha_{i j}$ and $\varepsilon_{i j}$ are no longer constant but are functions of the frequency and can diverge at the critical point.

The viscosities $\eta_{\mathrm{S}}$ and $\eta_{\mathrm{B}}$ being the most important transport coefficients for the sound propagation near the critical point, and, as shown by Kadanoff and Swift [1], $S_{q}, V_{q}^{\mathrm{T}}$ and their coupling being the relevant variables (i.e. the variables giving the strongest divergence at the critical point), we shall take for $\eta_{\mathrm{S}}$ and $\eta_{B}$ the formula obtained by Kawasaki in reference [2] and we shall neglect the frequency dependence of the other transport coefficients.

In an ultrasonic experiment, a transducer induces in the liquid a stationary sound wave of the form $\mathrm{e}^{-i(\omega t-k(\omega) x)}$ where

$$
k(\omega)=R(\omega)+i I(\omega) .
$$

The sound velocity is given by :

$$
C(\omega)=\frac{\omega}{R(\omega)}
$$

and the attenuation per wavelength by :

$$
\alpha(\omega)=2 \pi \frac{I(\omega)}{R(\omega)} .
$$

Using the equations (1), (2), (3), it is shown in reference [6] that $k(\omega)$ obeys the following dispersion equation

$$
\begin{aligned}
k^{4}(\omega) & \delta\left(i C_{0}^{2} / \gamma+\varphi(\omega) \omega\right)+ \\
+ & k^{2}(\omega)\left(C_{0}^{2} \omega-i \omega^{2}(\varphi(\omega)+\delta)\right)-\omega^{3}=0
\end{aligned}
$$

where

$$
\delta=\lambda / \rho C_{V}, \quad \gamma=C_{p} / C_{V}
$$

and

$$
\varphi(\omega)=\left(1+\frac{R \tau i \omega}{1-i \omega \tau}\right) \theta
$$

where $C_{p}$ and $C_{V}$ are the specific heat at constant pressure and constant volume, $C_{0}$ the zero frequency sound velocity, $\tau=2 \alpha_{22} / a$ the lifetime of the tensor $G_{\mathrm{s}}$ and $R=\alpha_{12}^{2} / \alpha_{22} \eta_{\mathrm{s}}$ the coupling factor between $(\nabla V)_{s}$ and the tensor $\vec{G}_{\mathrm{s}}$. The parameters $\tau$, and $R$ are phenomenological parameters and we can only assume from physical intuition that $\tau$ and $R$ increase when approaching the critical point. From thermodynamic considerations, we can also demonstrate that $R$ is always between zero and one [6]. To obtain more information about $\tau$ and $R$, it will be necessary, as said previously, to solve the complete mode mode coupling problem, without neglecting the density and the longitudinal velocity modes. This is a very difficult task and this is not the aim of this paper.

If we take $R=0$ or $\tau=0$ we obtain from (7) the classical dispersion equation [8]. This dispersion equation is also used by Sarid and Cannell [4]. We shall take for $\theta$ Kawasaki's prediction [2]. Therefore the equation (8) shows that the introduction of the $\overleftrightarrow{G}$ tensor gives for the frequency dependent viscosity $\varphi(\omega)$, the Kawasaki viscosity $\theta(\omega)$ multiplied by the relaxing term $\left(1+\frac{R \tau i \omega}{1-i \omega \tau}\right)$.

For ultrasonic experiments near the critical point of xenon $k \simeq \frac{\omega}{C(\omega)} \simeq 10^{4} \mathrm{~m}^{-1}$. From data collected by Swinney and Henry [9] we obtain $\delta \simeq 10^{-7} \mathrm{~m}^{2} / \mathrm{s}$. Far from the critical point $\theta$ is also of the order of $10^{-7} \mathrm{~m}^{2} / \mathrm{s}$ but increases very quickly near the critical point. It is thus possible to simplify with a good accuracy the dispersion equation (7) to obtain [4].

$$
k^{2}(\omega)\left(C_{0}^{2}-i \omega \varphi(\omega)\right)=\omega^{2} .
$$

Now using (5), (6), (8) and (9), we get, assuming $\theta$ real (see discussion below) :

$$
\omega_{\text {Real }} \varphi(\omega)=\omega \theta \frac{1+(1-R) \omega^{2} \tau^{2}}{1+\omega^{2} \tau^{2}}=\frac{2 C^{2}(\omega) \bar{\alpha}(\omega)}{\left(1+\bar{\alpha}^{2}(\omega)\right)^{2}}
$$

$$
\omega_{\operatorname{Im}} \varphi(\omega)=\frac{\theta R \omega^{2} \tau}{1+\omega^{2} \tau^{2}}=\frac{C^{2}(\omega)\left(1-\bar{\alpha}(\omega)^{2}\right)}{\left(1+\bar{\alpha}^{2}\right)^{2}}-C_{0}^{2}
$$

where $\bar{\alpha}=\alpha / 2 \pi$.

We shall compare the equations (10) and (11) with the experimental data of Mueller et al. [5].

The formula (11) shows two antagonistic processes. Approaching the critical temperature $T_{\mathrm{c}}, C_{0}$ decreases slowly towards zero, but $\theta$ diverges strongly. Thus the formula (11) indicates that the minimum of $C(\omega)$ could be observed for a temperature $T_{\mathrm{m}}$ higher than $T_{\mathrm{c}}$.

Therefore, to assume that $T_{\mathrm{c}}=T_{\mathrm{m}}$ is not a good approximation, even for the $1 \mathrm{kHz}$ experiments, we shall come back to this point later.

The choice of $T_{\mathrm{c}}$ is of crucial importance for analysing the experimental data. Swinney and Henry [9] give $T_{\mathrm{c}}=16.60^{\circ} \mathrm{C} \pm 0.01$ from light scattering expe- 
riments. This value is the most frequently used (see also for instance reference [10]). Nevertheless, the situation is not so clear concerning the analysis of ultrasonic experiments. For instance in reference [3] the authors choose $T_{\mathrm{c}}=16.953^{\circ} \mathrm{C}$ which corresponds to $T_{\mathrm{m}}$ of the $\mathrm{MHz}$ data given in reference [5]. But later Garland and Williams [11] find $T_{\mathrm{m}}=16.70^{\circ} \mathrm{C}$ for a frequency of $1 \mathrm{kHz}$ data. In their analysis Sarid and Cannell use three different values of $T_{\mathrm{c}}$. They choose $16.60^{\circ} \mathrm{C}$ for light scattering data, $16.70{ }^{\circ} \mathrm{C}$ for the $1 \mathrm{kHz}$ data and $16.953^{\circ} \mathrm{C}$ for the 1 and $3 \mathrm{MHz}$ data.

It is interesting to notice that the value

$$
T_{\mathrm{c}}=16.643^{\circ} \mathrm{C}
$$

obtained by Thoen and Garland by fitting their data is closer to $16.60^{\circ} \mathrm{C}$ than all the other determinations of $T_{\mathrm{c}}$ assuming that $T_{\mathrm{c}}=T_{\mathrm{m}}$. As it is difficult to assume that there are different values of $T_{c}$ following the type of experiment, we shall choose the more usually cited value, i.e. $T_{\mathrm{c}}=16.60^{\circ} \mathrm{C}$.

Kawasaki finds three different behaviours of $\theta$ following the value of $\omega^{*}=\frac{\omega \rho C_{p}}{2 \lambda} \xi^{2}$, where $\xi$ is the correlation length (see formula 2.4 and 3.10 and the discussion in reference [2]). Using reference [9] we get $\lambda / \rho C_{p}=0.936 \times 10^{-5} \mathrm{~cm}^{2} / \mathrm{s}$ for $T=17.56^{\circ} \mathrm{C}$.
From reference [9], we have also

$$
\xi=1.67\left(\frac{T-T_{\mathrm{c}}}{T_{\mathrm{c}}}\right)^{-0.63} \AA
$$

which gives $60.75 \AA$ for $T=17.56^{\circ} \mathrm{C}$. Using these values we get $\omega^{*} \simeq 0.12$ for $\omega=2 \pi \times 10^{6} \mathrm{~s}^{-1}$. Therefore if $T-T_{\mathrm{c}} \geqslant 1{ }^{\circ} \mathrm{C}$ and for $\omega$ in the $\mathrm{MHz}$ range we are essentially in Kawasaki's region I, i.e. $\omega^{*} \ll 1$. In this region $\theta$ is real and independent of the frequency.

Taking into account the uncertainty in estimating $\omega^{*}$ we shall assume in the analysis of the data that $\theta$ is real and independent of the frequency and we shall check the validity of this assumption.

In region I, Kawasaki [2] predicts a divergence law of the form $\theta=\theta_{0}\left(T-T_{\mathrm{c}}\right)^{-2+\alpha / 2}$. Kadanoff and Swift [1] predict in the same region a slightly different law $\theta \simeq\left(T-T_{\mathrm{c}}\right)^{-\gamma-v+3 \alpha / 2}$. Using the data of reference [9] we find $\theta=\theta_{0}\left(T-T_{\mathrm{c}}\right)^{-1.925}$ with $\theta_{0}=107 \times 10^{-6} \mathrm{~m}^{2} / \mathrm{s}$ for Kawasaki, and $\theta \simeq$ $\left(T-T_{\mathrm{c}}\right)^{-1.615}$ for Kadanoff and Swift.

We give in table $I$ the result of the analysis. For each frequency and each temperature, we give the theoretical and the experimental values of $2 C^{2} \bar{\alpha}$ and of $C(\omega)$. The experimental values are the upper figures. If we discard the point $T=19.736^{\circ} \mathrm{C}$,

Table I. - We express all the quantities in M.K.S.A. units. For each temperature and each frequency we give two figures for $2 C^{2} \bar{\alpha}$ and for $C$. The upper figures are the experimental data obtained from reference [5]. The

\begin{tabular}{|c|c|c|c|c|c|c|c|c|c|c|c|c|c|c|c|}
\hline \multirow[b]{2}{*}{$T$} & \multirow{2}{*}{$\begin{array}{c}2 \pi \tau \\
10^{-6}\end{array}$} & \multirow{2}{*}{$\begin{array}{c}2 \pi \theta \\
10^{-6}\end{array}$} & \multirow[b]{2}{*}{$R$} & \multicolumn{2}{|c|}{$0.4 \mathrm{MHz}$} & \multicolumn{2}{|c|}{$0.55 \mathrm{MHz}$} & \multicolumn{2}{|c|}{$1 \mathrm{MHz}$} & \multicolumn{2}{|c|}{$3 \mathrm{MHz}$} & \multicolumn{2}{|c|}{$5 \mathrm{MHz}$} & \multicolumn{2}{|c|}{$7 \mathrm{MHz}$} \\
\hline & & & & $2 C^{2} \bar{\alpha}$ & $C_{0}$ & $2 C^{2} \bar{\alpha}$ & $C$ & $2 C^{2} \bar{\alpha}$ & $C$ & $2 C^{2} \bar{\alpha}$ & $C$ & $2 C^{2} \bar{\alpha}$ & $C$ & $2 C^{2} \bar{\alpha}$ & $C$ \\
\hline 21.735 & 0.57 & 30.8 & 0.33 & & & $\begin{array}{c}16.5 \\
16.5\end{array}$ & \begin{tabular}{|c}
129.13 \\
129.0
\end{tabular} & $\begin{array}{l}28.6 \\
28.3\end{array}$ & $\begin{array}{l}128.95 \\
129.0\end{array}$ & $\begin{array}{r}72.2 \\
69.7\end{array}$ & \begin{tabular}{|l}
129.14 \\
129.0
\end{tabular} & $\begin{array}{l}105.0 \\
109.0\end{array}$ & $\begin{array}{l}129.04 \\
129.0\end{array}$ & $\begin{array}{l}149.0 \\
149.0\end{array}$ & $\begin{array}{l}128.93 \\
129.0\end{array}$ \\
\hline 20.735 & 0.61 & 43.0 & 0.31 & & & $\begin{array}{l}22.5 \\
22.9\end{array}$ & $\begin{array}{l}125.35 \\
125.0\end{array}$ & $\begin{array}{l}40.4 \\
39.4\end{array}$ & $\begin{array}{l}125.17 \\
125.0\end{array}$ & $\begin{array}{r}104.7 \\
98.4\end{array}$ & $\begin{array}{l}125.47 \\
125.0\end{array}$ & $\begin{array}{l}160.9 \\
155.1\end{array}$ & $\begin{array}{l}125.47 \\
125.0\end{array}$ & $\begin{array}{l}202.2 \\
213.0\end{array}$ & $\begin{array}{l}125.39 \\
125.0\end{array}$ \\
\hline 19.736 & 0.61 & 77.2 & 0.36 & & & $\begin{array}{l}40.8 \\
40.9\end{array}$ & $\begin{array}{l}120.75 \\
120.8\end{array}$ & $\begin{array}{l}69.2 \\
69.6\end{array}$ & \begin{tabular}{|l}
120.78 \\
120.8
\end{tabular} & $\begin{array}{l}170 \\
167\end{array}$ & $\begin{array}{l}120.74 \\
120.8\end{array}$ & $\begin{array}{l}259.0 \\
259.6\end{array}$ & $\begin{array}{l}121.15 \\
121.0\end{array}$ & $\begin{array}{l}289 \\
355\end{array}$ & $\begin{array}{l}121.28 \\
121.0\end{array}$ \\
\hline 18.735 & 0.69 & 166.0 & 0.54 & & & $\begin{array}{l}82.3 \\
85.2\end{array}$ & $\begin{array}{l}114.88 \\
115.0\end{array}$ & $\begin{array}{l}134.0 \\
137.0\end{array}$ & $\begin{array}{l}114.83 \\
115.1\end{array}$ & $\begin{array}{l}292 \\
282\end{array}$ & $\begin{array}{l}115.32 \\
115.4\end{array}$ & $\begin{array}{l}393.0 \\
420.0\end{array}$ & $\begin{array}{l}115.80 \\
115.4\end{array}$ & $\begin{array}{l}554 \\
565\end{array}$ & $\begin{array}{l}115.49 \\
115.4\end{array}$ \\
\hline 17.635 & 0.90 & 625.0 & 0.72 & & & $\begin{array}{l}295.0 \\
295.0\end{array}$ & $\begin{array}{l}104.66 \\
104.5\end{array}$ & $\begin{array}{l}421.0 \\
421.0\end{array}$ & $\begin{array}{l}105.14 \\
105.1\end{array}$ & $\begin{array}{l}680.0 \\
680.0\end{array}$ & $\begin{array}{l}105.95 \\
106.2\end{array}$ & & & & \\
\hline 17.336 & 1.14 & $\begin{array}{lll}1 & 120.0\end{array}$ & 0.80 & & & $\begin{array}{l}477.0 \\
477.0\end{array}$ & \begin{tabular}{|l|}
100.26 \\
101.0
\end{tabular} & $\begin{array}{l}617.0 \\
617.0\end{array}$ & $\begin{array}{l}101.25 \\
102.0\end{array}$ & $\begin{array}{l}912.0 \\
912.0\end{array}$ & \begin{tabular}{|l}
103.52 \\
103.8
\end{tabular} & & & & \\
\hline 17.136 & 1.48 & 2100.0 & 0.86 & & & $\begin{array}{l}743.0 \\
759.0\end{array}$ & $\begin{array}{l}96.61 \\
99.2\end{array}$ & $\begin{array}{l}859.0 \\
856.0\end{array}$ & $\begin{array}{c}98.21 \\
101.0\end{array}$ & $\mid \begin{array}{lll}1 & 123.0 \\
1 & 133.0\end{array}$ & $\begin{array}{l}100.37 \\
102.8\end{array}$ & & & & \\
\hline 17.028 & 2.32 & 4000.0 & 0.86 & $\begin{array}{l}964.0 \\
961.0\end{array}$ & $\begin{array}{l}92.94 \\
98.2\end{array}$ & $\begin{array}{ll}1 & 022.0 \\
1 & 029.0\end{array}$ & $\begin{array}{l}94.05 \\
99.2\end{array}$ & $\begin{array}{ll}1 & 132.0 \\
1 & 093.0\end{array}$ & $\begin{array}{c}96.12 \\
100.8\end{array}$ & & & & & & \\
\hline 17.003 & 2.83 & 4700.0 & 0.85 & $\begin{array}{l}994.0 \\
985.0\end{array}$ & $\begin{array}{l}92.92 \\
97.6\end{array}$ & $\begin{array}{ll}1 & 042.0 \\
1 & 039.0\end{array}$ & $\begin{array}{l}94.05 \\
98.7\end{array}$ & $\begin{array}{ll}1 & 172.0 \\
1 & 156.0\end{array}$ & $\begin{array}{c}96.22 \\
100.0\end{array}$ & & & & & & \\
\hline
\end{tabular}
lower figures are the theoretical values obtained from formula (10) and (11). 
$\omega=7 \mathrm{MHz}$, the discrepancy between the theoretical and the experimental values of $2 C^{2} \bar{\alpha}$ is always smaller than $5 \%$. We take $C_{0}$ from reference [11] where the authors give an experimental uncertainty of $\pm 1 \mathrm{~m} / \mathrm{s}$. Therefore we find a good agreement between the experimental and the theoretical values of $C(\omega)$ for $T \geqslant 17.336^{\circ} \mathrm{C}$. For the lower values of $T$ the agreement between the theoretical and the experimental values of $C(\omega)$ is not good. This is due to the fact that the assumption that $\theta$ is real and frequency independent is no longer valid.

The shear viscosity $\eta_{\mathbf{S}}$ has been measured near the xenon critical point [13]. There is a weak divergence but $\eta_{\mathrm{s}} / \rho_{\mathrm{c}}$ is never larger than $6 \times 10^{-8} \mathrm{~m}^{2} / \mathrm{s}$. Thus even for $T=21.735^{\circ} \mathrm{C}, \theta$ is three order of magnitude larger than $\eta_{\mathrm{S}} / \rho_{\mathrm{c}}$ and we can identify with a very good accuracy $\theta$ with the bulk viscosity $\eta_{\mathrm{B}} / \rho_{\mathrm{c}}$.

In the figure 1 , we show, on a $\log -\log$ plot, $\theta$ as a function of $T-T_{\mathrm{c}}$. We find a critical behaviour $\theta=\theta_{0}\left(T-T_{\mathrm{c}}\right)^{-a}$ with $a=1.92 \pm 0.04$ and $\theta_{0}=(110 \pm 5) \cdot 10^{-6} \mathrm{~m}^{2} / \mathrm{s}$, in very good agreement with Kawasaki's prediction.

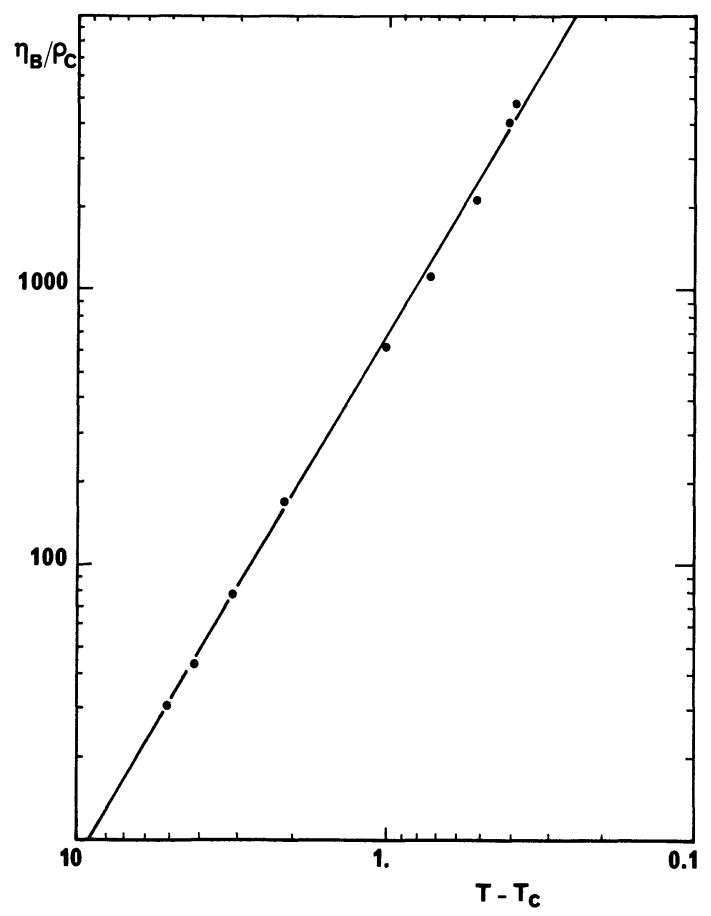

Fig. 1. - Bulk viscosity as a function of $T-T_{\mathrm{c}}$ in a log-log plot. We take $T_{\mathrm{c}}=16.60^{\circ} \mathrm{C}$. The viscosity $\eta_{\mathrm{B}} / \rho_{\mathrm{c}}$ is expressed in $\mathrm{m}^{2} /(2 \pi \mathrm{s})$. The slope of the straight line is equal to $1.92 \pm 0.04$.

We would like to come back to the experiments of Garland and Williams [11]. They measure the velocity of the sound at the frequency of $1 \mathrm{kHz}$, and they find a minimum for $T_{\mathrm{m}}=16.70^{\circ} \mathrm{C}$. If we choose $T_{\mathrm{c}}=16.60$ we can compute $\omega^{*}$ for $T_{\mathrm{m}}$ using reference [9]. We get $\omega^{*} \simeq 0.01$. Therefore, we are in region $I$ where the formula (11) is correct, and where $\theta$ has the critical behaviour given above. If we compute its value we get $\theta \simeq 1.3 \times 10^{-2} \mathrm{~m}^{2} / \mathrm{s}$.

We take the relaxation time $\tau$ to be of the order of $10^{-4} \mathrm{~s}$, and $R$ to be of the order of 1 .

Using these values we get for the dispersive term in formula (11),

$$
\frac{\theta R \omega^{2} \tau}{1+\omega^{2} \tau^{2}} \simeq 37 \mathrm{~m}^{2} / \mathrm{s}^{2}
$$

Therefore there is a non negligible difference between $C_{0}$ and $C(1 \mathrm{kHz})$ for $T=16.70^{\circ} \mathrm{C}$. This difference increases when approaching the critical temperature. This analysis could explain why the minimum of $C(1 \mathrm{kHz})$ is not observed for the usual value $T_{\mathrm{c}}=16.60^{\circ} \mathrm{C}$ but for the higher value $T=16.70{ }^{\circ} \mathrm{C}$. The difference between $C(1 \mathrm{kHz})$ and $C_{0}$ is negligible for $T \geqslant 17^{\circ} \mathrm{C}$.

In conclusion, we emphasize in this paper that the choice of $T_{\mathrm{c}}$ is of crucial importance in the analysis of the ultrasonic data. We choose the usual value $T_{\mathrm{c}}=16.60 \pm 0.01$. From this choice we show that the frequency dependence of the absorption and of the dispersion of the sound observed for $T-T_{\mathrm{c}} \geqslant 1{ }^{\circ} \mathrm{C}$ cannot be explain by Kawasaki's formula, because in this range of temperature he predicts too small an absorption and dispersion. We believe that this discrepancy is due to the fact that he has neglected the density-density mode coupling. On the other hand, the local-order theory takes into account this mode coupling, but this is a phenomenological theory, which predicts the frequency dependence of the absorption and of the dispersion, but does not give the divergence of the viscosity due to the entropyentropy mode coupling. Kawasaki predicts this divergence with a law $\theta=\theta_{0}\left(T-T_{\mathrm{c}}\right)^{-1.92}$.

We show in this analysis, that for $T-T_{\mathrm{c}} \geqslant 1{ }^{\circ} \mathrm{C}$, the local-order theory gives an accurate description of the experimental dispersion and absorption. From this analysis we obtain the viscosity $\theta$ and we show that the divergence law is in good agreement with Kawasaki's prediction.

Acknowledgments. - This letter is the continuation of a work begun at M.I.T. in the Department of Chemistry. The author would like to thank Prof. Oppenheim for enlightening conversations and his kind hospitality during this stay. He acknowledges also conversations with Prof. Garland.

\section{References}

[1] Kadanoff, L. P. and Swift, J., Phys. Rev. 166 (1968) 89.

[2] Kawasaki, K., Phys. Rev. 11 (1970) 1750.
[3] Eden, D., Garland, C. and Thoen, J., Phys. Rev. Lett. 28 (1972) 726. 
See also Garland, C., Eden, D. and Mistura, L., Phys. Rev. Lett. 25 (1970) 1161.

[4] Sarid, D., Cannell, D. S., Phys. Rev. A 15 (1977) 735.

[5] Mueller, P. E., Eden, D., Garland, C. W. and Williamson, R. C., Phys. Rev. A 6 (1972) 2272.

[6] QuentreC, B. and OPPENheim, I., Physica 92 (1978) A 42.

[7] Quentrec, B., J. Physique 37 (1976) 1255.

[8] De Groot and MazUR, Non Equilibrium Thermodynamics (North Holland) 1969, chapter XII.
[9] Swinney, H. L. and Henry, D. L., Phys. Rev. A 8 (1973) 2586. [10] Cannell, D. S. and Benedeck, G. B., Phys. Rev. Lett. 25 (1970) 1157.

[11] Garland, C. W. and Williams, R. D., Phys. Rev. A 10 (1974) 1328.

[12] Thoen, J. and Garland, C. W., Phys. Rev. A 10 (1974) 1311.

[13] Strumpf, H. J., Colings, A. F. and Pings, C. J., J. Chem. Phys. 60 (1974) 3109. 